\title{
Docosahexaenoic acid intake decreases proliferation, increases apoptosis and decreases the invasive potential of the human breast carcinoma cell line MDA-MB-231
}

\author{
VINCENT BLANCKAERT $^{1,2}$, LIONEL ULMANN $^{1,2}$, VIRGINIE MIMOUNI $^{1,2}$, \\ JOHANN ANTOL $^{3}$, LUCILE BRANCQUART ${ }^{1}$ and BENOÎT CHÉNAIS ${ }^{1}$ \\ ${ }^{1}$ Université du Maine, EA2160 Mer Molécules Santé, Le Mans, F-72085; ${ }^{2}$ IUT de Laval, Département Génie Biologique, \\ Laval, F-53020; ${ }^{3}$ INSERM U908, Université de Lille, Villeneuve d'Ascq, F-59655, France
}

Received July 29, 2009; Accepted September 18, 2009

DOI: 10.3892/ijo_00000549

\begin{abstract}
Breast cancer is the most common cancer in women in industrialized countries. Environmental factors, such as differences in diet are likely to have an important influence on cancer emergence. Among these factors, $n-3$ polyunsaturated-fatty acids, such as docosahexaenoic acid (DHA), are good candidates for preventing breast cancer. Here we investigate the effect of DHA on the human breast cancer cell line MDA-MB-231 and show that DHA incorporation i) has an anti-proliferative effect, ii) induces apoptosis via a transient increase in caspase- 3 activity and the promotion of nuclear condensation, and iii) reduces the invasive potential of MDA-MB-231 cells. To conclude, DHA may have beneficial effects as a result of slowing the proliferation of tumor cells, and minimizing their metastatic potential.
\end{abstract}

\section{Introduction}

For several decades, genetic and environmental factors have been explored in order to elucidate the appearance of tumors. Genetic factors are obviously involved in carcinogenesis, but diet is an environmental factor that is likely to have an influence on health (1), and particularly on tumor emergence (2-4). It has been shown that $\mathrm{n}-3$ polyunsaturated, long-chain fatty acids (PUFAs), such as docosahexaenoic acid (DHA) or eicosapentaenoic acid (EPA), are able to play an important preventive role in cardiovascular disease (5) and cancer (6). This conclusion is based partly on the observation that the incidence of these diseases is lower in Japanese people,

Correspondence to: Dr Vincent Blanckaert, EA2160-MMS, IUT de Laval, Département Génie Biologique, 52 rue des Docteurs Calmette et Guérin, BP2045, 53020 Laval Cedex 9, France

E-mail: vblanck@univ-lemans.fr

Key words: apoptosis, breast cancer, carcinoma cell, docosahexaenoic acid, invasion, polyunsaturated fatty acid whose diet is seafood based, resulting in a more balanced ratio between $n-3$ and $n-6$ PUFA than that of the Western diet (7). Even though this resource may be depleted in the future by the overharvesting of n-3 PUFA rich fish, it could be replaced by using marine microalgae, which have been identified as an important alternative source of DHA and EPA $(8,9)$. Breast cancer is one of the cancers most frequently observed in industrialized countries, and the one with the highest incidence in women. Epidemiological studies have shown that the rate of breast cancer is 4 to 5 times higher in Western countries than in Japan $(1,10)$. The mechanism by which DHA and EPA could provide protection against the appearance of a tumor, or directly influence cancer cells by reducing their malignancy, remains unclear, since cohort studies do not reveal any correlation between fat intake and breast cancer (1). Nevertheless, some evidence hints that DHA not only acts as an anti-proliferative agent by lengthening the cell cycle between the G2/M transition (11), but is also a proapoptotic factor, increasing caspase-3 and Bax $(12,13)$. In addition, DHA has been shown to affect cell proliferation, whatever its source (i.e., fish oil or microalgae) (14). It has also been shown that the n-3 PUFAs and DHA, in particular, can act on lipid peroxidation as well as on the proteins implicated in the ROS mechanism leading to cell death $(15,16)$.

In this study, the effects of two concentrations of DHA (20 and $100 \mu \mathrm{M}$ ) were investigated on the human breast cancer cell line MDA-MB-231. DHA incorporation into the cells was first monitored, and then its inhibitory effect on cell proliferation was observed. The findings demonstrate the apoptosis-promoting effect of DHA, evidenced by a transient increase in caspase- 3 activity, and an enhanced level of nuclear condensation. Finally, DHA was shown to reduce the invasive phenotype of the MDA-MB-231 cell line, for at least 4 passages of the cell culture. This study provides new insights into the timing sequence of the effects of DHA, which could prove useful for future functional and mechanistic investigations.

\section{Materials and methods}

Cell culture. The breast cancer cell line MDA-MB-231 was obtained from the American Type Culture Collection, and 
routinely grown as monolayers at $37^{\circ} \mathrm{C}$ in a humidified atmosphere of $5 \% \mathrm{CO}_{2}$ in minimum essential medium (MEMEarle's salts, Sigma-Aldrich, Saint Quentin Fallavier, France) supplemented with $10 \%$ fetal calf serum (FCS, Invitrogen, Cergy-Pontoise, France), 20 mM HEPES, 2 mM L-glutamine, $100 \mathrm{U} / \mathrm{ml}$ penicillin/streptomycin and $0.4 \mathrm{mg} / \mathrm{ml}$ insulin.

Proliferation and viability assays. The subconfluent cells grown in $75-\mathrm{cm}^{2}$ flasks were rinsed twice with $10 \mathrm{ml}$ PBS. Two milliliters of non-enzymatic dissociation solution (Sigma-Aldrich) were added to the flasks. The dissociated cells were counted using a Malassez hematocytometer, and 200,000 cells in MEM containing 5\% FCS were loaded into a fresh $75-\mathrm{cm}^{2}$ flask, and grown until they reached $70 \%$ confluence. MEM (10 ml) containing 5\% FBS, with or without 20 or $100 \mu \mathrm{M}$ DHA (Sigma-Aldrich) were added to the flasks, and changed every $24 \mathrm{~h}$. Untreated and DHAtreated cells were dissociated with $2 \mathrm{ml}$ of non-enzymatic dissociation solution after 24,48 or 72 h. After homogenizing, cell viability was determined using the Trypan blue dye exclusion test (Sigma-Aldrich), and counts were performed using a Malassez hemocytometer. The remaining cells were washed with $10 \mathrm{ml}$ sterile phosphate buffer saline (PBS), and centrifuged for $10 \mathrm{~min}$ at $200 \mathrm{x} \mathrm{g}$. The pellet was homogenized, washed again with PBS, and centrifuged under the same conditions. The supernatants were discarded, and the cells were either used without delay, or kept at $-70^{\circ} \mathrm{C}$ for further experiments. Four independent experiments were conducted, each in triplicate.

DHA incorporation assay and total fatty acid analysis. Lipids were extracted from the tissues using dimethoxymethane/methanol (4/1, v/v) according to Delsal (17). After drying with ethanol, the samples were dissolved in $1 \mathrm{ml}$ of chloroform, and transferred to methylation vials. After evaporating under nitrogen, $1 \mathrm{ml}$ of $\mathrm{NaOH}(0.5 \mathrm{~N})$ in methanol solution was added. Samples were covered by nitrogen to prevent oxidation, and then incubated for $20 \mathrm{~min}$ at $80^{\circ} \mathrm{C}$. This first step corresponded to saponification. The transmethylation step was then conducted according to the method of Slover and Lanza (18) as follows: $2 \mathrm{ml}$ of boron trifluoride methanol $\left(\mathrm{BF}_{3}-\mathrm{MeOH} 14 \%\right.$, Sigma-Aldrich) were added to the samples, which were incubated as described above. The fatty acid methyl esters (FAMEs) were extracted using $1 \mathrm{ml}$ of iso-octane (trimethyl-pentane), and dried on an anhydrous sodium sulfate column. This operation was conducted twice. FAMEs were analyzed by gas-liquid chromatography using a GC Focus (Thermo Fisher Scientific, Courtaboeuf, France) equipped with a Thermo TR-FAME $30 \mathrm{~m}$ x $0.25 \mathrm{~mm}$ i.d. capillary column (Thermo Fisher Scientific). Analyses were carried out from 120 to $220^{\circ} \mathrm{C}$ with a $6^{\circ} \mathrm{C} / \mathrm{min}$ gradient. The AS $3000 \mathrm{split} / \mathrm{splitless}$ autosampler (Thermo Fisher Scientific) and detector temperatures were 250 and $280^{\circ} \mathrm{C}$, respectively. The esters were detected with a flame-ionization detector (air, hydrogen, 29 and 14.5 psi, respectively). The FAMEs were identified by comparing with the corresponding commercial standards (189-1 and 189-15, Sigma-Aldrich). Results are expressed as molar percentage of total saturated fatty acids (SFA, 14:0, 16:0 and 18:0), total monounsaturated fatty acids (MUFA, 16:1n-7 and 18:1n-9), and total polyunsaturated fatty acids (n-6 PUFA; 18:2, 18:3, 20:4, 22:5; and n-3 PUFA; 18:4, 20:5, 22:6) for 24,48 and $72 \mathrm{~h}$ of incubation with or without 20 or $100 \mu \mathrm{M}$ DHA.

Caspase-3 assay. The Caspase-3 Colorimetric Assay Kit from Sigma Aldrich is based on the hydrolysis of acetyl-AspGlu-Val-Asp p-nitroanilide (Ac-DEVD-pNA) by caspase-3, resulting in the release of the p-nitroaniline (pNA) moiety. Assays were performed according to the manufacturer's method. Briefly, pellets of $5 \times 10^{6}$ cells were lysed in $50 \mu 1 \mathrm{XX}$ lysis buffer and incubated on ice for $20 \mathrm{~min}$. The lysed cells were centrifuged at $16,000 \mathrm{xg}$ for $15 \mathrm{~min}$ at $4^{\circ} \mathrm{C}$. The supernatants were transferred into new tubes. Lysates were then frozen and stored at $70^{\circ} \mathrm{C}$ until use. Assays were performed with $15 \mu 1$ of cell lysates, $980 \mu 11 \mathrm{X}$ assay buffer and $10 \mu \mathrm{l}$ ac-DEVD-pNA, and compared with a blank prepared with $990 \mu 11 \mathrm{X}$ assay buffer and $10 \mu \mathrm{l}$ substrate. The tubes were covered, and the incubation performed at $37^{\circ} \mathrm{C}$ for $90 \mathrm{~min}$. Absorbance was read at $405 \mathrm{~nm}$. Caspase-3 activity in terms of $\mu \mathrm{mol}$ of pNA released per min per $\mathrm{ml}$ was obtained by the following formula: $\mathrm{A}_{405 \mathrm{~nm}} \times \mathrm{d} / \varepsilon^{\mathrm{mM}} \times \mathrm{t} \mathrm{x} \mathrm{v}$; where $\varepsilon^{\mathrm{mM}}=10.5$; $\mathrm{v}$, volume of sample in $\mathrm{ml}$; $\mathrm{d}$, dilution factor; $\mathrm{t}$, reaction time in min. Four independent experiments were conducted, each in duplicate.

Invasion assay and Hoechst staining. Invasion assays were done in 12-well Boyden microchambers (Transwell ${ }^{\circledR}$, Fisher Scientific, Illkirch, France) with $8-\mu \mathrm{m}$ pore membranes. Matrigel $^{\circledR}(100 \mu \mathrm{l})$ (BD Science, Le Pont de Claix, France) at $10 \%$ in MEM were introduced in the upper chamber and dried overnight at $37^{\circ} \mathrm{C}$. Cells were treated with 20 or $100 \mu \mathrm{M}$ DHA for $24,48,72 \mathrm{~h}$ in $25-\mathrm{cm}^{2}$ flasks. At the selected time, the cells were dissociated with a non-enzymatic dissociation solution, and counted by using a Malassez hematocytometer. Living cells $(40,000)$ treated with or without DHA in $400 \mu \mathrm{l}$ MEM supplemented with $0.5 \%$ FCS and $1 \%$ BSA were then loaded into the upper chamber. A volume of $800 \mu 1$ of MEM with $0.5 \%$ FCS, and $1 \%$ BSA was introduced into the lower chamber. After incubating for $24 \mathrm{~h}$, the Transwell were rinsed with PBS, and the Matrigel was scraped off the upper surfaces of the membranes. The cells remaining on the underside of the membrane were fixed for $30 \mathrm{~min}$ at $20^{\circ} \mathrm{C}$ in methanol, stained with Hoechst stain (Sigma-Aldrich), and mounted on glass slides with glycerol before counting (20 fields per membrane) under a UV microscope. Three independent experiments were performed, each in duplicate.

In order to appreciate the long-term effect on invasion, the cells were incubated in the presence or absence of $100 \mu \mathrm{M}$ DHA for $72 \mathrm{~h}$, and either immediately used for invasion assay, (corresponding to passage, $\mathrm{P} 0$ ) or diluted in a new culture flask in the absence of DHA before being harvested (P1-P6). Cells were harvested and cultured with MEM containing 5\% FCS, and their invasive potential was assayed after $72 \mathrm{~h}$ in Boyden chambers, as described above. These assays were performed for each stage in triplicate.

Statistical analysis. Statistical studies were performed using $\mathrm{KyPlot}^{\circledR}$ for a one-way ANOVA followed by a Dunnett's test. 


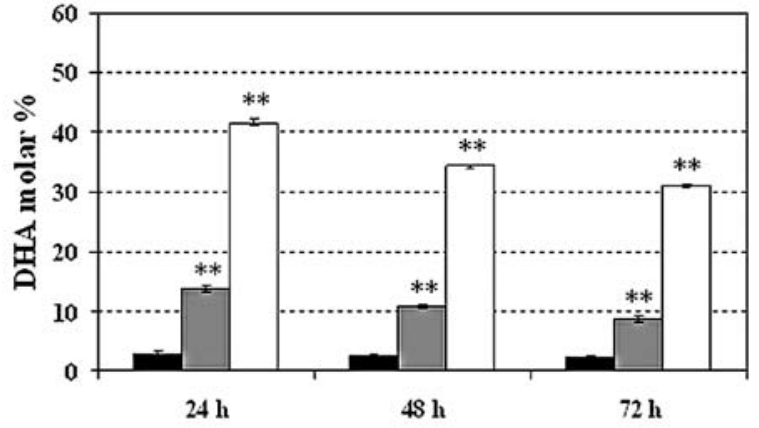

Figure 1. Relative percentage of DHA in total lipid from MDA-MB-231 cells after incubating for 24, 48 and $72 \mathrm{~h}$. Black bars correspond to control without any exogenous DHA; gray and white bars correspond to incubation with 20 and $100 \mu \mathrm{M}$ DHA, respectively. Results are the mean \pm S.D. of 2 independent experiments each done in triplicate. Statistical significance was assayed using one-way ANOVA, followed by a Dunnett's test. ${ }^{* *} \mathrm{P} \leq 0.01$.
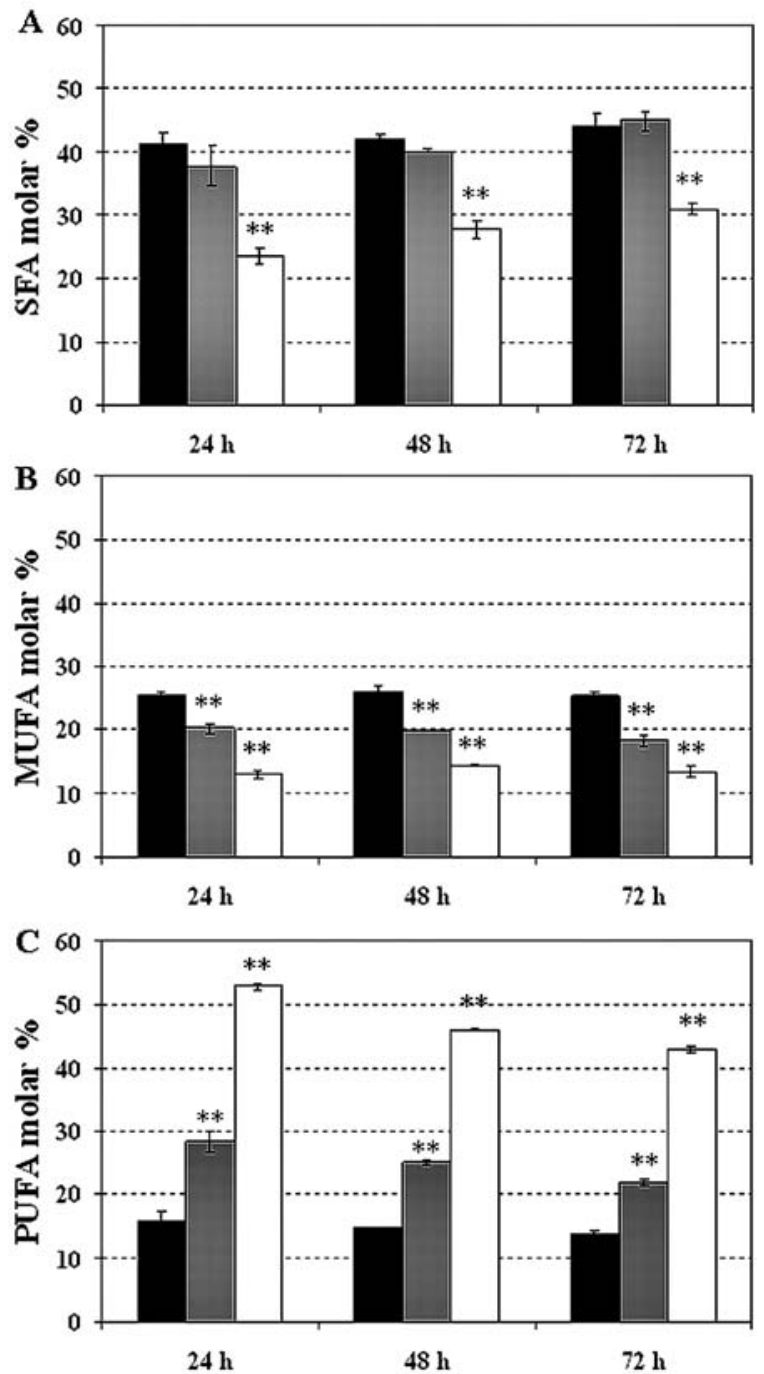

Figure 2. Total lipid fatty acid composition of MDA-MB-231 cells after incubating for 24, 48 and $72 \mathrm{~h}$. Results are expressed as the molar percentage of total lipids for (A) saturated, (B) monounsaturated and (C) polyunsaturated fatty acids. Black bars correspond to control without any exogenous DHA; gray and white bars correspond to incubation with 20 and $100 \mu \mathrm{M}$ DHA, respectively. Results are the mean \pm S.D. of 2 independent experiments each done in triplicates. Statistical significance was assayed using one-way ANOVA followed by a Dunnett's test. ${ }^{* *} \mathrm{P} \leq 0.01$.

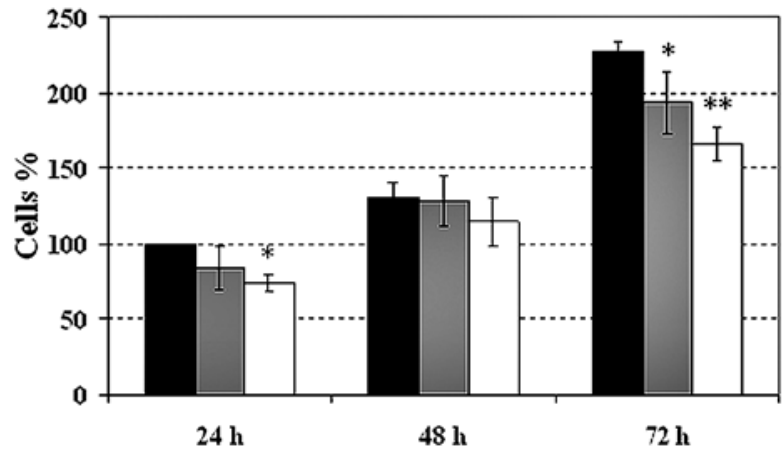

Figure 3. Effect of DHA on MDA-MB-231 cell line proliferation. Percentages were obtained by comparing the number of cells under a given set of conditions to the number of cells corresponding to the 24-h control. Black bars correspond to control without any exogenous DHA; gray and white bars correspond to 20 and $100 \mu \mathrm{M}$ DHA, respectively. Results are the mean \pm S.D. of 4 independent experiments each done in triplicate. Statistical significance was assayed using ANOVA followed by Dunnett's test with the control of the different time of incubation as reference. ${ }^{*} \mathrm{P} \leq 0.05 ;{ }^{* *} \mathrm{P} \leq 0.01$.

\section{Results}

Incorporation of DHA in the MDA-MB-231 cell line and total lipid fraction composition. The incorporation of exogenous DHA was estimated by determining the molar percentage of DHA in the total lipid fraction, after incubating with 20 or $100 \mu \mathrm{M}$ of DHA. By comparison with the control (DHA level in the total lipid fraction in the absence of exogenous DHA), the results reported in Fig. 1 show the dose-dependent increase in the DHA level, which rose by 13 and $41 \%$ with 20 and $100 \mu \mathrm{M}$ of exogenous DHA, respectively. Whichever exogenous DHA concentration was used, the cellular DHA level peaked after incubation for $24 \mathrm{~h}$, and decreased slightly thereafter.

The effect of incubating in exogenous DHA on the composition of the total lipid fraction was analyzed by measuring the change in the molar percentage of SFA, MUFA and PUFA over time in the presence or absence of exogenous DHA. SFAs were unchanged in the presence of $20 \mu \mathrm{M}$ DHA, but decreased when exposed to $100 \mu \mathrm{M}$ DHA for 24-72 $\mathrm{h}$ (Fig. 2A). The proportion of MUFA was reduced in a dosedependent manner after incubating with DHA for 24-72 h (Fig. 2B). In contrast, PUFAs increased dramatically in the presence of DHA; this increase was dose-dependent and peaked after incubating for $24 \mathrm{~h}$ (Fig. 2C).

Effect of DHA on MDA-MB-231 cell proliferation. As shown in Fig. 3, cell proliferation decreased slightly following DHA treatment. This effect was statistically significant at the $72 \mathrm{~h}$ time point for both DHA concentrations. Cell proliferation was also reduced by incubation with DHA, with a significant reduction after exposure to $100 \mu \mathrm{M}$ DHA for $24 \mathrm{~h}$. No significant difference was noted for the $48 \mathrm{~h}$ incubation time for either DHA concentration.

Effect of DHA on caspase-3 activity and nucleus condensation. In order to show that the DHA-induced reduction of cellular proliferation and/or viability was due at least in part to apoptosis, caspase- 3 activity was determined in MDA-MB231 cells after incubating with DHA. The results clearly 


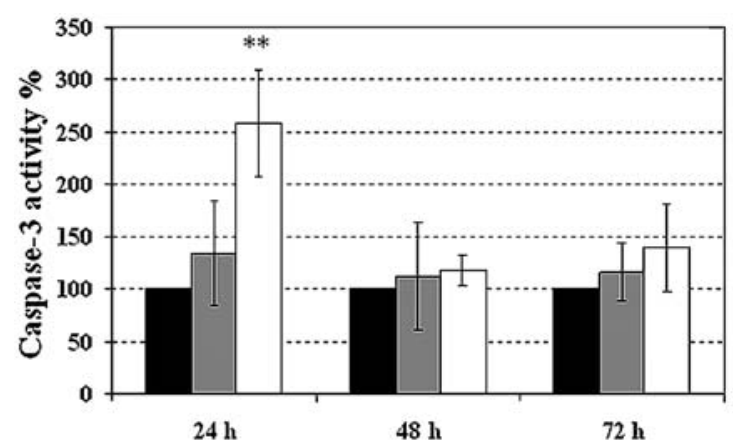

Figure 4. Caspase-3 activity in MDA-MB-231 cells incubated with DHA. Black bars correspond to control without any exogenous DHA; gray and white bars correspond to incubation with 20 and $100 \mu \mathrm{M}$ DHA, respectively. The caspase-3 activity was determined using Ac-DEVD-pNA as a substrate as detailed in Materials and methods and compared to the corresponding value in control. Results are the mean \pm S.D. of 4 independent experiments each done in duplicate. Statistical significance was assayed using one-way ANOVA followed by a Dunnett's test. ${ }^{* *} \mathrm{P} \leq 0.01$.
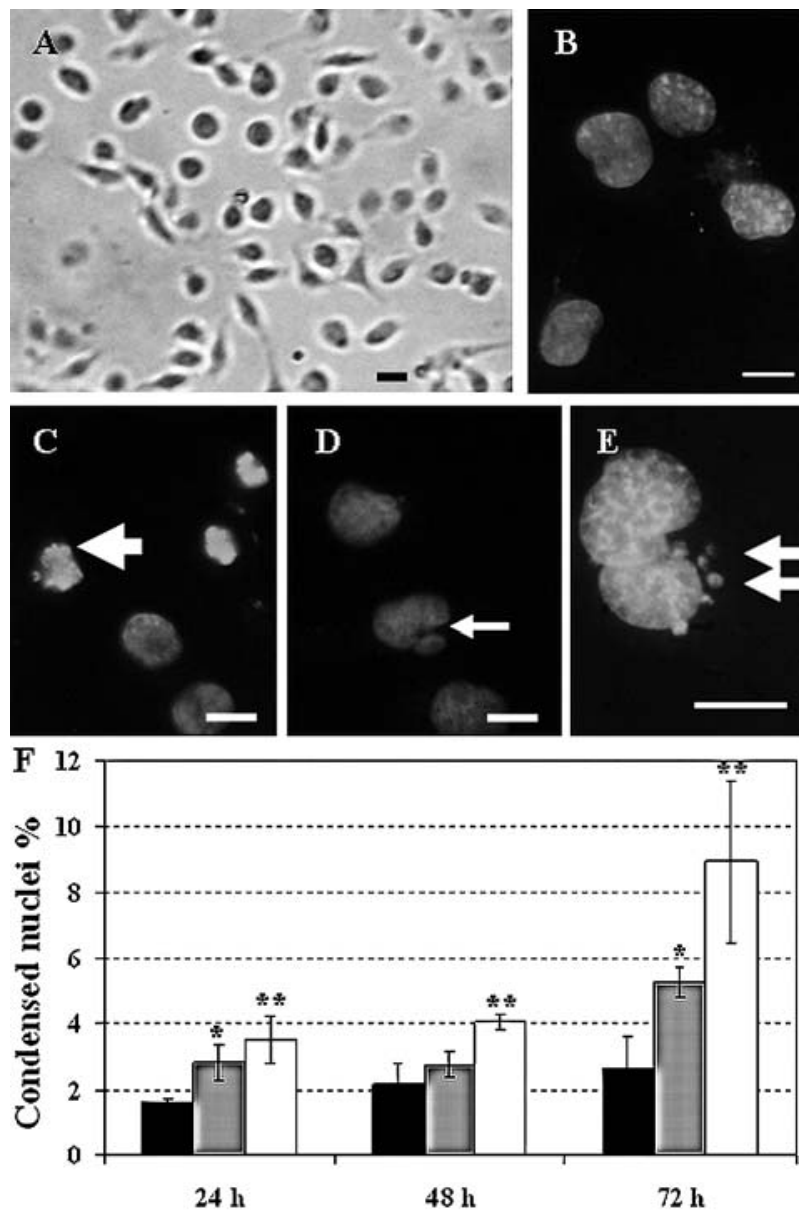

Figure 5. Effect of DHA on programmed cell death. (A) Light micrograph of MDA-MB-231 cells in culture. (B-E) Fluorescent micrographs of Hoechst stained nuclei: (B) normal nuclei; (C) condensed nucleus (arrow); (D) fragmented nucleus (arrow); (E) fragmented nucleus or apoptotic bodies (arrows). When the nucleus had undergone multiple fragmentations, this was scored as one event. Bars correspond to $25 \mu \mathrm{m}$. (F) Appearance of condensed nuclei in DHA-treated MDA-MB-231 cells. Black bars correspond to control without any exogenous DHA; gray and white bars correspond to incubation with 20 and $100 \mu \mathrm{M}$ DHA, respectively. Results are the mean \pm S.D. of 3 independent experiments each done in duplicate. Statistical significance was assayed using one-way ANOVA followed by a Dunnett's test. * $\mathrm{P} \leq 0.05$; ${ }^{* *} \mathrm{P} \leq 0.01$.
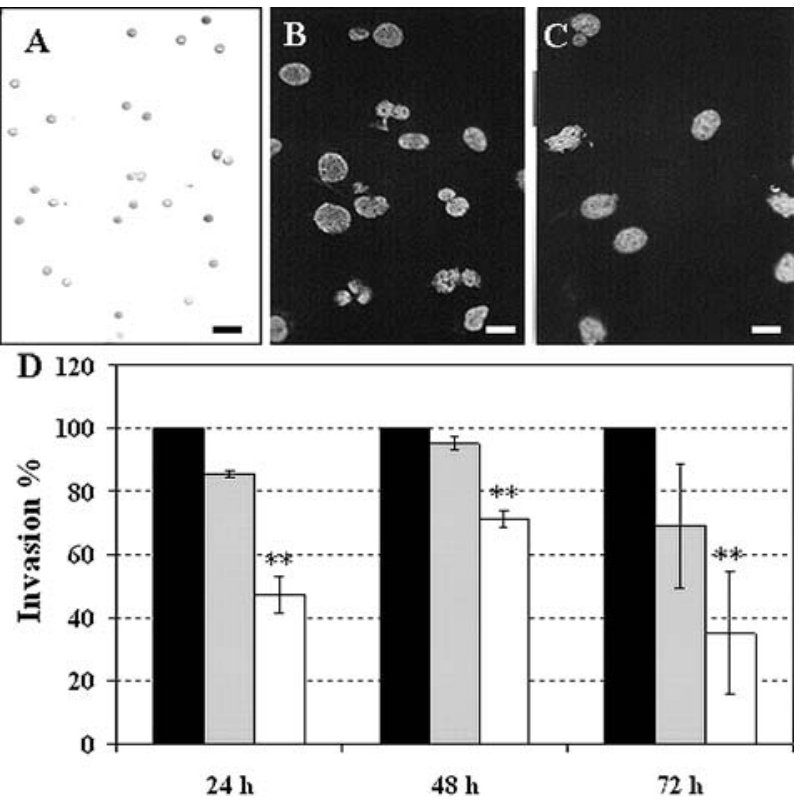

Figure 6. Effect of DHA on the invasive potential of MDA-MB-231 cells. (A) Micrograph of an $8-\mu \mathrm{m}$ Boyden chamber filter taken under a light microscope. (B-C) Hoechst-stained nuclei of untreated and treated MDAMB-231 cells with $100 \mu \mathrm{M}$ DHA for $72 \mathrm{~h}$ able to pass through the Matrigel, and the $8-\mu \mathrm{m}$ filter, respectively. Bars correspond to $25 \mu \mathrm{m}$. (D) Twenty microscopic fields were randomly chosen for nucleus counts of treated and untreated cells presenting a metastatic phenotype. Black bars correspond to control without any exogenous DHA; gray and white bars correspond to incubation with 20 and $100 \mu \mathrm{M}$ DHA, respectively. Results are the mean \pm S.D. of 3 independent experiments each done in duplicate. Statistical significance was assayed using one-way ANOVA followed by a Dunnett's test. ${ }^{* *} \mathrm{P} \leq 0.01$

show a strong albeit transient increase in caspase-3 activity after $24 \mathrm{~h}$ in the presence of $100 \mu \mathrm{M}$ DHA (Fig. 4, P $\leq 0.01$ ). Caspase-3 activity then fell to close to the control level for longer incubation times. Although not statistically significant, a similar pattern of caspase-3 activity was observed with $20 \mu \mathrm{M}$ DHA, suggesting a dose-effect of DHA (Fig. 4).

Since chromatin condensation is a hallmark of apoptosis, Hoechst staining of nuclei was performed of untreated control cells and after incubating some cells with DHA. The slides were observed under a fluorescence microscope, and normal and condensed nuclei were counted. Some examples of micrographs showing Hoechst-stained nuclei are shown in Fig. 5 B-E, and correspond to the nuclei of MDA-MB-231 cells observed in Fig. 5A. Some nuclei appeared to be condensed or fragmented (arrows).

Incubating MDA-MB-231 cells with DHA resulted in a dose- and time-dependent increase in condensed apoptotic nuclei (Fig. 5F). A concentration of $100 \mu \mathrm{M}$ DHA significantly impacted the percentage of apoptosis $(\mathrm{P} \leq 0.01)$. A trend towards an increasing percentage of cells in apoptosis was observed with DHA, suggesting a dose-effect; the percentage of apoptosis being representative of nucleus condensation. With $100 \mu \mathrm{M}$ DHA, the percentage of condensed nuclei increased between the different time points, and peaked $(\mathrm{P} \leq 0.01)$ at between 5 and $11 \%$ after incubating for $72 \mathrm{~h}$ under our experimental conditions.

Effect of DHA on the invasive phenotype of MDA-MB-231 cells. The invasive potential of the cells was assayed using 


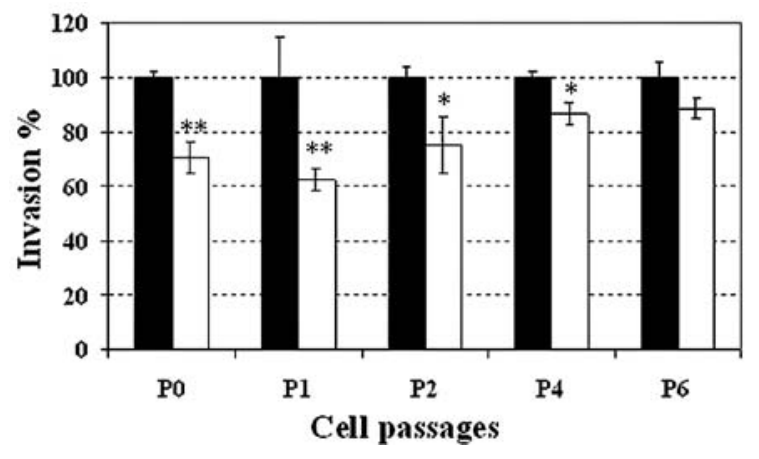

Figure 7. Long-term effect of DHA on the invasive potential of MDA-MB-231 cells. After a 72 h DHA treatment, cells were grown with MEM containing $10 \%$ FCS for several passages (P0-P6). Prior to invasion assay, the cells were placed in MEM containing $1 \%$ FCS, and the study was carried out as detailed in the Material and methods section. Black bars correspond to the control without incubation with DHA, and white bars correspond to cells previously incubated with $100 \mu \mathrm{M}$ DHA for $72 \mathrm{~h}$. P number corresponds to the different passage. Results are the mean \pm S.D. of 2 independent experiments each done in triplicates. Statistical significance was assayed using one-way ANOVA followed by a Dunnett's test. ${ }^{*} \mathrm{P} \leq 0.05 ;{ }^{* *} \mathrm{P} \leq 0.01$.

Boyden chambers, and cells were considered to be invasive if they were able to get through both the layer of Matrigel, and the $8-\mu \mathrm{m}$ porosity filter. The micrographs showing an $8-\mu \mathrm{m}$ pore filter from a Boyden chamber, and Hoechst-stained nuclei of untreated and DHA-treated cells are shown in Fig. 6A-C. The nuclei counts showed that the proportion of invasive cells was markedly decreased following incubation with $100 \mu \mathrm{M}$ of DHA for 24-72 h (Fig. 6D). However, the results obtained at the lower DHA concentration (i.e., $20 \mu \mathrm{M}$ ) were not statistically significant.

Furthermore, the inhibitory effect of DHA on the invasive potential of MDA-MB-231 cells was investigated in longterm experiments, in which cells were maintained in culture for several passages after DHA treatment. The results showed that the DHA-induced reduction of invasive cells number was sustained for 4 passages, and then became less marked (Fig. 7).

\section{Discussion}

Docosahexaenoic acid intake reduces cell proliferation. DHA can produce this effect at a relatively weak concentration, but with an incubation time of $72 \mathrm{~h}$. The number of dead cells increased slightly over time (data not shown), but the absence of any statistically significant evidence suggests that DHA was not cytotoxic. The obvious question is therefore how DHA induces a reduction in proliferation. Several studies have shown that it might be acting at the level of the cell cycle, by increasing the duration of the cycle, and more particularly that of the G2/M transition step (11). This is thought to be caused by the inhibition of the CDK1-cyclin B 1 complex by DHA. Consequently, the fact that the untreated cells continued a normal cell cycle would explain the reduction of cell numbers during the course of DHA treatment.

Another parameter could also be involved, as we have demonstrated that DHA acts on the cells in the short-term by activating caspase-3, an apoptosis effector enzyme. However, the dramatic fall in this activity over longer-term suggests that there could be two populations within the cell line, only one of which is sensitive to the caspase-3 pathway. As previously described, MDA-MB-231 cells can activate the caspase-3 pathway via polyunsaturated fatty acids (19). Thus, early activation of this enzymatic activity, resulting in the rapid death of this population, would be compatible with the fall in cell number observed in Fig. 3, where a difference in terms of proliferation was noted at $24 \mathrm{~h}$ for levels of $100 \mu \mathrm{M}$ (leading to a greater difference in terms of cell losses compared to the untreated cells). Evidence of increased apoptosis was also provided by counting the number of condensed nuclei. These data showed that the effect of DHA on MDA-MB-231 cells eventually involved the morphological changes typical of apoptosis. However, these data seemed to contradict those obtained by means of the caspase- 3 assay, which displayed activation after $24 \mathrm{~h}$. This implies that a more significant number of condensed nuclei would have been visible at 24 and $48 \mathrm{~h}$. It is probable that the cells, having reacted to DHA by activating caspase- 3 , had completely disappeared by $48 \mathrm{~h}$, and this might explain the low incidence of condensed nuclei; several hours were generally needed to ensure that a cell went through the phenomenon of complete apoptosis once it had undergone the action of caspase-3. Indeed, the increasing numbers of condensed nuclei, which under our conditions reached their highest level of $11 \%$ after a longer incubation time, was consistent with the study reported by Siddiqui et al (20), in which the percentage of cells undergoing apoptosis leveled off at $15 \%$. It is also possible that DHA can induce several different pathways leading to apoptosis, and in particular, the Bax pathway that has been described for the HL60 cell line (13). This could account for the delayed appearance of condensed cores. Besides, other authors have shown that DHA has a cytotoxic effect on cancer cells by decreasing the level of superoxide dismutase 1 , allowing an increase in lipid peroxidation to occur (21). It is probable that these 3 pathways are all involved in cells exposed to DHA. This suggests that DHA could reduce tumor numbers by acting as soon as a cell begins to change and becomes pre-cancerous; this might explain the low level of breast cancer in populations with a high DHA diet.

One of the main problems in breast cancer, as well as in other types of cancer, is the ability of cancer cells to metastasize. Several studies have shown that diet can affect the metastatic potential of cancer cell lines known to have a high metastatic phenotype. This effect may be either transient or lasting. For instance, providing the highly metastatic B16BL6 melanoma cell line with low levels of phenylalanine and tyrosine can result in cells with a lower metastatic potential (2). DHA appears to affect the invasive potential of MDA-MB-231 cells, which implies that it could modify their metastatic phenotype. By extrapolation, this is interesting, because it highlights the importance of the $\omega-3$ fatty acids as compounds that could protect against the appearance of breast cancers or their recurrence (22). However, the mechanisms by which DHA could directly affect the metastatic phenotype of cancer cell lines remain unclear. The effect of DHA could result to some extent from a change in the lipids 
present in the membrane of the cells, making their plasma membrane considerably less fluid. If this is so, the lower invasive capacity would be explained by a reduction in the deformability of the cells (23). However, our findings showed that i) no reduction in the metastatic phenotype was detected when cells were treated with $20 \mu \mathrm{M}$ DHA, whatever the incubation time, and ii) cells treated with $100 \mu \mathrm{M}$ DHA for $72 \mathrm{~h}$ conserved a lower metastatic phenotype at least for a limited number of cell cycles after being returned to a normal medium. Thus, it would be too restrictive to suggest that the level of DHA incorporated alone affects the metastatic phenotype. It is probable that other factors are involved, particularly those that are known to produce the degradation of the Matrigel, which mimics the extracellular matrix (ECM), to occur. Indeed, to be able get across the ECM, the metastatic cells have both the enzymatic tools to digest it, and a composition of integrins that differs from that of normal cells (24). Another possible hypothesis is that DHA, and perhaps other n-3 PUFAs, are able to compartmentalize at the level of the plasma membrane molecules or membrane proteins in particular structures, such as lipid rafts, that are now considered to be important in cell signaling $(25,26)$.

To conclude, it looks as though, depending on the amount present, DHA might play an important role in the processes by which normal and/or differentiated cells gain certain characteristics, allowing them to slow their proliferation and minimize their metastatic potential. This finding could be useful in proteomic analyses to decipher the proteins implicated in these phenomena, and should make it possible to clarify the mechanisms and pathways controlling them.

\section{Acknowledgements}

The authors are grateful to Monika Gosh for English revision of the manuscript. We wish to thank Professor Hubert Hondermarck for his encouragement and helpful advice. This work was supported by a Grant from the Mayenne Collectivities.

\section{References}

1. Holmes $\mathrm{M}$ and Willett W: Does diet affect breast cancer risk? Breast Cancer Res 6: 170-178, 2004.

2. Blanckaert VD, Schelling ME, Elstad CA and Meadows GG: Differential growth factor production, secretion, and response by high and low metastatic variants of B16BL6 melanoma. Cancer Res 53: 4075-4081, 1993.

3. Greenwald P, Clifford CK and Milner JA: Diet and cancer prevention. Eur J Cancer 37: 948-965, 2001.

4. Molokhia E and Perkins A: Preventing cancer. Prim Care 35: 609-623, 2008

5. Russo GL: Dietary n-6 and n-3 polyunsaturated fatty acids: From biochemistry to clinical implications in cardiovascular prevention. Biochem Pharmacol 77: 937-946, 2009.

6. Berquin IM, Edwards IJ and Chen YQ: Multi-targeted therapy of cancer by omega-3 fatty acids. Cancer Lett 269: 363-377, 2008.

7. Hwang D, Chanmugam P, Ryan D, Boudreau M, Windhauser M, Tulley R, Brooks E and Bray G: Does vegetable oil attenuate the beneficial effects of fish oil in reducing risk factors for cardiovascular disease? Am J Clin Nutr 66: 89-96, 1997.
8. Ward OP and Singh A: Omega-3/6 fatty acids: alternative sources of production. Process Biochem 40: 3627-3652, 2005.

9. Van Beelen VA, Spenkelink B, Mooibroek H, Sijtsma L, Bosch D, Rietjens IM and Alink GM: An n-3 PUFA-rich microalgal oil diet protects to a similar extent as a fish oil-rich diet against AOM-induced colonic aberrant crypt foci in F344 rats. Food Chem Toxicol 47: 316-320, 2009.

10. Kinlen L: Diet and breast cancer. Br Med Bull 47: 462-469, 1991.

11. Barascu A, Besson P, Le Floch O, Bougnoux P and Jourdan M-L: CDK1-cyclin B 1 mediates the inhibition of proliferation induced by omega-3 fatty acids in MDA-MB-231 breast cancer cells. Int J Biochem Cell Biol 38: 196-208, 2006.

12. Chamras H, Ardashian A, Heber D and Glaspy JA: Fatty acid modulation of MCF-7 human breast cancer cell proliferation, apoptosis and differentiation. J Nutr Biochem 13: 711-716, 2002.

13. Miura Y, Takahara K, Murata Y, Utsumi K, Tada M and Takahata K: Docosahexaenoic acid induces apoptosis via the Bax-independent pathway in HL-60 cells. Biosci Biotechnol Biochem 68: 2415-2417, 2004.

14. Judé S, Roger S, Martel E, Besson P, Richard S, Bougnoux P, Champeroux $\mathrm{P}$ and Le Guennec J-Y: Dietary long-chain omega-3 fatty acids of marine origin: a comparison of their protective effects on coronary heart disease and breast cancers. Prog Biophys Mol Biol 90: 299-325, 2006.

15. Vibet S, Goupille C, Bougnoux P, Steghens J-P, Goré J and Mahéo K: Sensitization by docosahexaenoic acid (DHA) of breast cancer cells to anthracyclines through loss of glutathione peroxidase (GPx1) response. Free Radic Biol Med 44: 1483-1491, 2008.

16. Siddiqui RA, Harvey K and Stillwell W: Anticancer properties of oxidation products of docosahexaenoic acid. Chem Phys Lipids 153: 47-56, 2008.

17. Delsal J: Nouveau procédé d'extraction des lipides du sérum par le méthylal. Application aux micro-dosages du cholestérol total, des phosphoamino-lipides et des protéines. Bull Soc Chim Biol 26: 99-105, 1944.

18. Slover HT and Lanza E: Quantitative analysis of food fatty acids by capillary gas chromatography. J Am Oil Chem Soc 56: 933-943, 1979.

19. Winnicka K, Bielawski K, Bielawska A and Surazynski A: Antiproliferative activity of derivatives of ouabain, digoxin and proscillaridin A in human MCF-7 and MDA-MB-231 breast cancer cells. Biol Pharm Bull 31: 1131-1140, 2008.

20. Siddiqui R, Zerouga M, Wu M, Castillo A, Harvey K, Zaloga G and Stillwell W: Anticancer properties of propofoldocosahexaenoate and propofol-eicosapentaenoate on breast cancer cells. Breast Cancer Res 7: 645-654, 2005.

21. Ding W, Vaught J, Yamauchi H and Lind S: Differential sensitivity of cancer cells to docosahexaenoic acid-induced cytotoxicity: the potential importance of down-regulation of superoxide dismutase 1 expression. Mol Cancer Ther 3: 1109-1117, 2004.

22. Stoll B: Breast cancer and the Western diet: role of fatty acids and antioxidant vitamins. Eur J Cancer 34: 1852-1856, 1998.

23. Zerouga M, Jenski LJ, Booster S and Stillwell W: Can docosahexaenoic acid inhibit metastasis by decreasing deformability of the tumor cell plasma membrane? Cancer Lett 119: 163-168, 1997.

24. Seiki M: Membrane-type 1 matrix metalloproteinase: a key enzyme for tumor invasion. Cancer Lett 194: 1-11, 2003.

25. Stillwel IW, Shaikh S, Zerouga M, Siddiqui R and Wassall S: Docosahexaenoic acid affects cell signaling by altering lipid rafts. Reprod Nutr Dev 45: 559-579, 2005.

26. Biondo PD, Brindley DN, Sawyer MB and Field CJ: The potential for treatment with dietary long-chain polyunsaturated n-3 fatty acids during chemotherapy. J Nutr Biochem 19: 787-796, 2008. 